\title{
A Natural History Study of Nitrous Oxide versus Propofol-Assisted Intrathecal Therapy in the Treatment of Acute Lymphoblastic Leukemia
}

\author{
Lane Miller ${ }^{1}$, Stuart Winter ${ }^{2}$, David Watson ${ }^{3}$, mylynda livingston ${ }^{4}$, Resty Nemata ${ }^{2}$, and \\ Yoav Messinger ${ }^{5}$ \\ ${ }^{1}$ Children's Minneapolis \\ ${ }^{2}$ Children's Minnesota \\ ${ }^{3}$ Children's Hospitals and Clinics of Minnesota \\ ${ }^{4}$ Children's MN \\ ${ }^{5}$ Children's Hospitals \& Clinics of Minnesota
}

September 25, 2021

\begin{abstract}
Background: Childhood acute lymphoblastic leukemia (ALL) treatment requires numerous lumbar punctures (LPs) with intrathecal (IT) chemotherapy to prevent and treat central nervous system disease. Historically, LPs in this setting are performed using propofol sedation. At our institution, LPs are often alternatively performed under nitrous oxide (N2O). To date, there have been no large scale assessments comparing these sedation methods for this purpose. Procedures: Retrospective cohort study of patients aged 0-31 years with ALL treated between 1/1/2013-12/31/2018 at the Children's Minnesota Cancer and Blood Disorders Center, including all therapeutic LPs performed in the clinic setting under either propofol or N2O. Results: Among 215 patients and 2677 therapeutic LPs, 56.6\% ( $\mathrm{n}=1515)$ occurred under N2O with $43.3 \%(\mathrm{n}=93)$ of patients using exclusively $\mathrm{N} 2 \mathrm{O}$ with all LPs. The incidence of traumatic LPs (RBC [?] 10 cells/ $\mu \mathrm{L}$ ) were similar between both treatments (27.3\% vs 30.2). Successful IT chemotherapy delivery (99.7\% N2O vs $99.8 \%$ propofol) did not differ between sedation types. Experiencing a traumatic LP under N2O was associated with a sedation switch for the subsequent LP (aOR 2.40, p=0.002) while older age (aOR 1.08, p<0.0001) and higher BMI percentile (aOR 1.01, $\mathrm{p}=0.009)$ were associated with increased likelihood for undergoing a traumatic LP. Conclusion: N2O is an effective sedation option for therapeutic LPs in children with ALL with noninferiority to propofol in terms of IT chemotherapy administration and traumatic LP incidence. For many patients, N2O can effectively replace propofol during LP procedures, which has important safety and quality-of-life implications.
\end{abstract}

A Natural History Study of Nitrous Oxide versus Propofol-Assisted Intrathecal Therapy in the Treatment of Acute Lymphoblastic Leukemia

Lane H Miller MD $\mathrm{MSc}^{1}$, Stuart S Winter $\mathrm{MD}^{1}$, Dave Watson $\mathrm{PhD}^{2}$, Mylynda Livingston $\mathrm{CNP}^{1}$, Resty Nemata $^{3}$, and Yoav Messinger MD ${ }^{1}$

From the Cancer and Blood Disorders, ${ }^{1}$ the Design and Analytics Programs, ${ }^{2}$ and ITS Data Systems ${ }^{3}$, Children's Minnesota, Minneapolis, MN 55404

Address correspondence to:

Lane Miller, MD MSc

Cancer and Blood Disorders Program 
2525 Chicago Avenue South

Minneapolis, MN 55404

lane.miller@childrensmn.org

Abstract word count: 249

Main text word count: 1870

Number of tables: 3

Number of figures: 2

Running title: Nitrous oxide versus propofol-assisted intrathecal therapy in ALL

Keywords: leukemia, pediatric, sedation, lumbar puncture, intrathecal, supportive care

Meeting abstracts:

Miller LH, Winter S, Watson D, Livingston M, Messinger Y. (2021) Comparing effectiveness of nitrous oxide and propofol-assisted lumbar punctures in childhood acute lymphoblastic leukemia. Oral presentation at the Children's Remarkable Research Conference, May 2021.

Miller LH, Livingston M, Watson D, Winter S, Messinger Y. (2020) Comparing effectiveness of nitrous oxide, propofol, and midazolam-assisted lumbar punctures in childhood acute lymphoblastic leukemia. Poster at the American Society of Hematology Annual Meeting, December 2020.

Miller LH, Finch M, Livingston M, Winter S, Messinger Y. (2020) Comparing effectiveness and safety of nitrous oxide versus propofol-assisted sedation for lumbar punctures in childhood acute lymphoblastic leukemia. Poster at the American Society of Pediatric Hematology and Oncology Annual Meeting, May 2020 .

Miller LH, Finch M, Livingston M, Winter S, Messinger Y. (2020) Comparing effectiveness and safety of nitrous oxide versus propofol-assisted sedation for lumbar punctures in childhood acute lymphoblastic leukemia. Poster at the 2020 Children's Remarkable Research Conference.

Abbreviation Key:

\begin{tabular}{ll}
\hline Abbreviation & Complete Term \\
\hline ALL & acute lymphoblastic leukemia \\
LP & lumbar puncture \\
IT & intrathecal \\
$\mathrm{N}_{2} \mathrm{O}$ & nitrous oxide \\
$\mathrm{OR}$ & odds ratio \\
aOR & adjusted odds ratio \\
$\mathrm{CI}$ & confidence interval \\
$\mathrm{CNS}$ & central nervous system \\
$\mathrm{NPO}$ & nil per os \\
$\mathrm{BMI}$ & body-mass index \\
$\mathrm{CSF}$ & cerebrospinal fluid \\
RBC & red blood cell \\
ANOVA & analysis of variance \\
\hline
\end{tabular}

Abstract :

Background: 
Childhood acute lymphoblastic leukemia (ALL) treatment requires numerous lumbar punctures (LPs) with intrathecal (IT) chemotherapy to prevent and treat central nervous system disease. Historically, LPs in this setting are performed using propofol sedation. At our institution, LPs are often alternatively performed under nitrous oxide $\left(\mathrm{N}_{2} \mathrm{O}\right)$. To date, there have been no large scale assessments comparing these sedation methods for this purpose.

Procedures:

Retrospective cohort study of patients aged 0-31 years with ALL treated between 1/1/2013-12/31/2018 at the Children's Minnesota Cancer and Blood Disorders Center, including all therapeutic LPs performed in the clinic setting under either propofol or $\mathrm{N}_{2} \mathrm{O}$.

Results:

Among 215 patients and 2677 therapeutic LPs, $56.6 \%(\mathrm{n}=1515)$ occurred under $\mathrm{N}_{2} \mathrm{O}$ with $43.3 \%(\mathrm{n}=93)$ of patients using exclusively $\mathrm{N}_{2} \mathrm{O}$ with all LPs. The incidence of traumatic LPs (RBC [?] 10 cells/ $\mu \mathrm{L}$ ) were similar between both treatments $(27.3 \%$ vs 30.2$)$. Successful IT chemotherapy delivery $\left(99.7 \% \mathrm{~N}_{2} \mathrm{O}\right.$ vs $99.8 \%$ propofol) did not differ between sedation types. Experiencing a traumatic LP under $\mathrm{N}_{2} \mathrm{O}$ was associated with a sedation switch for the subsequent LP (aOR 2.40, $\mathrm{p}=0.002)$ while older age $(\mathrm{aOR} 1.08, \mathrm{p}<0.0001)$ and higher BMI percentile (aOR 1.01, $\mathrm{p}=0.009$ ) were associated with increased likelihood for undergoing a traumatic LP.

Conclusion:

$\mathrm{N}_{2} \mathrm{O}$ is an effective sedation option for therapeutic LPs in children with ALL with noninferiority to propofol in terms of IT chemotherapy administration and traumatic LP incidence. For many patients, $\mathrm{N}_{2} \mathrm{O}$ can effectively replace propofol during LP procedures, which has important safety and quality-of-life implications.

\section{Introduction :}

Conventional treatment for B-lineage and T-lineage childhood acute lymphoblastic leukemia (ALL) and lymphoma includes anywhere from 16-30 lumbar punctures (LPs) with intrathecal (IT) chemotherapy in order to prevent and/or treat central nervous system (CNS) leukemia ${ }^{1-4}$. Historically, LPs in children are performed using propofol as a sedative-hypnotic agent, which has a strong and lengthy record of attaining deep sedation with rapid onset in the clinic setting ${ }^{5-7}$, but is unfortunately limited by requiring a nil per os (NPO) status and, due to the small but not insignificant risk of hypotension and respiratory depression, entails management by a provider skilled in airway management. Each of these caveats can result in timing, patient quality-of-life, and safety limitations.

At our institution, many outpatient LPs alternatively incorporate inhaled nitrous oxide $\left(\mathrm{N}_{2} \mathrm{O}\right)$ as a sedation agent ${ }^{8,9}$. The decision to provide $\mathrm{N}_{2} \mathrm{O}$ or propofol is ultimately made by a patient's care team during a visit prior to the actual sedation and based on a variety of real-world factors, including patient age, patient anatomy (body-mass index (BMI), scoliosis), patient temperament, patient and parent preference, and prior experience with the various sedation methods. $\mathrm{N}_{2} \mathrm{O}$ has a well-established, safe history of alleviating pain and anxiety with rapid onset in children undergoing various procedures, including LPs, although with the unfortunate caveat of providing only moderate sedation and carrying the possible hazards of provider drug exposure and SARS-CoV-2 aerosolization in presymptomatic or asymptomatic patients ${ }^{8-12} \cdot \mathrm{N}_{2} \mathrm{O}$ does not carry the same cardiopulmonary risks and can be administered regardless of NPO status.

To date, there have been no large scale assessments comparing these sedation methods for the purpose of performing therapeutic LPs in children with leukemia. The primary aim of this retrospective study was to assess the patterns of use of $\mathrm{N}_{2} \mathrm{O}$ and propofol as sedation methods when conducting LPs with IT chemotherapy administration in children with ALL. Secondary aims included comparing the effectiveness of $\mathrm{N}_{2} \mathrm{O}$ and propofol sedation for this purpose and identifying factors associated with selection of one sedation agent over the other, switching from one sedation agent to the other, and obtaining a traumatic LP under a given sedation choice. 


\section{Methods :}

Study design and population:

We conducted a retrospective cohort study of patients with ALL treated between 1/1/2013-12/31/2018 at the Children's Minnesota Cancer and Blood Disorders Center, including all LPs performed in the clinic setting. LPs performed in conjunction with bone marrow aspirations/biopsies or diagnostic LPs without the intent of providing IT chemotherapy were excluded from the dataset. Our study population included patients who had undergone a minimum of 5 LPs to allow for adequate within-subject data to better characterize sedation trajectories over time. Patients who received $>2$ of their LPs under an alternative sedation regimen (e.g. midazolam monotherapy) were excluded from this analysis. Any sedated LP using a sedation regimen other than $\mathrm{N}_{2} \mathrm{O}$ or propofol were removed from the dataset. Subjects were considered $\mathrm{N}_{2} \mathrm{O}$ or propofol-predominant if they underwent $>90 \%$ of all clinic LPs under that particular sedation agent. Subject data was collected from the data warehouse and electronic health records. The study was approved by the Children's Minnesota Institutional Review Board.

Study variables:

For the purpose of assessing efficacy, each individual LP was evaluated as a discrete event. Demographic data (age, sex, race/ethnicity, language, BMI), encounter-specific data (sedation choice, concurrent midazolam administration, child life involvement), and outcomes (successful IT chemotherapy administration, CSF (cerebrospinal fluid) RBCs (red blood cells), number of LP attempts) were abstracted. A 'traumatic' LP was defined as any LP with a CSF RBC value [?] 10 cells/ $\mu \mathrm{L}$. BMI was presented as a percentile based on age and gender appropriate WHO growth charts and included weight-for-length percentiles as a substitute in children $<2$ years of age.

Statistical methods:

Comparisons between $\mathrm{N}_{2} \mathrm{O}$ and propofol sedated patients were made using ANOVA, two-sample T tests, $\chi^{2}$ tests, and Fisher's exact tests where appropriate. Random effects logistic regression was used to model associations with two outcomes: switching sedation agents and obtaining a traumatic LP. Clinically relevant factors included in the model were sedation agent used, number of previous LPs, description of previous LP (i.e. traumatic LP, child life involvement), age, BMI, language, and race/ethnicity. Outcomes from a patient's first LP were not included because the models incorporated information from the previous LP. Random effects for patients were used to account for within-patient correlation. Results are reported as adjusted odds ratios (aOR) with $95 \%$ confidence intervals (CI).

Results :

There were a total of 215 subjects (Figure 1) who received 2677 clinic LPs, $56.6 \%(\mathrm{n}=1515)$ of which were performed under $\mathrm{N}_{2} \mathrm{O}$ sedation and $43.4 \%(\mathrm{n}=1162)$ under propofol sedation. Midazolam was used as an anxiolytic in conjunction with $5.5 \%(\mathrm{n}=84)$ of all $\mathrm{N}_{2} \mathrm{O}$ LPs and $2.6 \%(\mathrm{n}=30)$ of all propofol LPs. $\mathrm{N}_{2} \mathrm{O}$ was exclusively used for all LPs in $43.3 \%(\mathrm{n}=93)$ of patients compared to propofol for $22.3 \%(\mathrm{n}=48)$. The plurality of patients $(45.1 \%, \mathrm{n}=97)$ were $\mathrm{N}_{2} \mathrm{O}$-predominant whereas $29.8 \%(\mathrm{n}=64)$ and $25.1 \%(\mathrm{n}=54)$ were propofol-predominant or had no overwhelming sedation preference, respectively (Table 1).

IT chemotherapy was unable to be given in only $0.2 \%(\mathrm{n}=6)$ of all LPs, of which 4 were under $\mathrm{N}_{2} \mathrm{O}$ and 2 under propofol. A traumatic LP was obtained in $28.6 \%(\mathrm{n}=760)$ of all LPs. This occurred $30.2 \%$ of the time $(\mathrm{n}=348)$ under propofol sedation and $27.3 \%$ of the time $(\mathrm{n}=412)$ under $\mathrm{N}_{2} \mathrm{O}$ sedation.

The mean BMI percentile was significantly higher among the propofol-predominant patients when compared to nitrous-predominant patients and those with no sedation preference $(65.8 \%$ vs $50.7 \%$ vs $52.3 \%$, p = 0.01). There were no statistically significant differences in these groups in terms of gender, age at first LP, or race/ethnicity (Table 1$)$. Twenty-five percent $(\mathrm{n}=29)$ of the $0-5.99$ year old group were propofolpredominant, compared to $34.6 \%(\mathrm{n}=18)$ and $36.2 \%(\mathrm{n}=17)$ of the $6-12.99$ and $13-30.99$ year old groups 
$(\mathrm{p}=0.38)$. Among the Hispanic patients, $56.3 \%(\mathrm{n}=9)$ were propofol-predominant compared to $30.3 \%(\mathrm{n}$ $=43), 27.3 \%(\mathrm{n}=3), 35.3 \%(\mathrm{n}=6)$ of white, black, and Asian patients $(\mathrm{p}=0.06)$.

$\mathrm{N}_{2} \mathrm{O}$ was the sedation agent of choice in $72.1 \%(\mathrm{n}=155)$ of the first clinic LPs performed, however this proportion declined with subsequent LPs, including $66.1 \%(\mathrm{n}=142)$ of second and $47.9 \%(\mathrm{n}=103)$ of final clinic LPs (Figure 2). Among those patients who received $\mathrm{N}_{2} \mathrm{O}$ for their first clinic LP, $11.6 \%(\mathrm{n}=18)$ switched to propofol for the subsequent LP. Among those patients, $88.9 \%(\mathrm{n}=16)$ never reattempted $\mathrm{N}_{2} \mathrm{O}$. Child life was present for $40.2 \%(\mathrm{n}=1075)$ of total procedures, including $18.8 \%$ of propofol procedures $(\mathrm{n}$ $=218)$ and $56.6 \%$ of $\mathrm{N}_{2} \mathrm{O}$ procedures $(\mathrm{n}=857)$.

A multivariate model demonstrated that switching sedation agents with the subsequent LP is primarily associated with the previous sedation agent used and the previous LP outcome, with patients switching from $\mathrm{N}_{2} \mathrm{O}$ to propofol more often than vice versa, and in particular when the previous LP was traumatic (Table 2). Specifically, the odds of switching after an atraumatic LP was 0.37 (95\% CI: 0.16-0.84) times lower for propofol than $\mathrm{N}_{2} \mathrm{O}$ while after a traumatic LP, the odds were 0.13 (95\% CI: 0.04-0.39) times lower for propofol than $\mathrm{N}_{2} \mathrm{O}$. A prior traumatic LP did not change the odds of switching under a previous propofol sedation (aOR $0.82,95 \%$ CI: 0.28-2.42), but it did change the odds of switching after a previous $\mathrm{N}_{2} \mathrm{O}$ sedation (aOR 2.40, 95\% CI: 1.39-4.15). As an example of these associations, we considered the probability of switching sedation agents after an LP. The probability of switching to propofol after a prior $\mathrm{N}_{2} \mathrm{O}$ LP was 0.05 if the $\mathrm{LP}$ was atraumatic and 0.11 if the LP was traumatic. In contrast, the probability of switching to $\mathrm{N}_{2} \mathrm{O}$ if the prior LP was under propofol was the same at 0.02 , whether or not the LP was traumatic. The number of previous LPs a subject had undergone was associated with a reduced likelihood of switching to the alternate sedation with the next LP (aOR 0.89, 95\% CI: 0.83-0.95).

A multivariate model demonstrated that the odds of a traumatic LP are comparable for propofol and $\mathrm{N}_{2} \mathrm{O}$ sedations (Table 3; aOR 0.99, 95\% CI 0.76-1.28). Older age (aOR 1.08, 95\% CI 1.05-1.10), higher BMI percentile (aOR 1.01, 95\% CI 1.00-1.01), and midazolam use with the prior LP (aOR 2.23, 95\% CI 1.38-3.63) were significantly and independently associated with an increased likelihood for experiencing a traumatic LP.

\section{Discussion :}

In this large retrospective assessment of sedation methods for the purpose of performing LPs with IT chemotherapy in children with ALL, we report that $\mathrm{N}_{2} \mathrm{O}$ has been adopted as the most commonly used sedation option in our clinic. We undertook the creation of an $\mathrm{N}_{2} \mathrm{O}$ program at the request of our patients, families, and providers to address a variety of quality-of-life considerations. It serves as the sedation agent of choice in the majority of all therapeutic LPs and nearly 3 in 4 first clinic LPs while a plurality of patients use $\mathrm{N}_{2} \mathrm{O}$ exclusively for all clinic LPs. Moreover, it has been shown to be highly effective and equivalent to propofol in terms of successful IT chemotherapy administration and traumatic LP incidence.

While patients in our cohort were not randomly assigned to one sedation method or another, a difference in discretionary sedation selection is evident. Our demographic data supports a preference for providing propofol to patients with elevated BMIs. This suggests a set of unmeasured criteria (e.g. patient temperament, parent interest, provider comfort) that may underlie the initial sedation allocation. A significant proportion of patients $(40 \%)$ trialed $\mathrm{N}_{2} \mathrm{O}$ initially in the treatment course but ultimately transitioned permanently to propofol sedation for reasons to be determined. Once a patient has set forth on a particular sedation route for the remainder of therapy, the likelihood of persevering with that sedation for the next LP relies predominantly on the number of prior LPs the patient has undergone, the sedation choice that was used for the most recent LP, and if they received $\mathrm{N}_{2} \mathrm{O}$, whether a traumatic LP occurred with the most recent LP. This collective data complements those factors associated with successful LPs cited in the pediatric literature, such as local anesthetic use, child life involvement, hypnosis, and virtual reality ${ }^{13-16}$.

In terms of limitations, there is certainly a subjective aspect to the patient, parent, and provider experience during an LP that is not addressed here in the data, as intimated above. Additionally, as is inherent to retrospective studies in general, there may be critical measurable variables and confounders that were not 
represented.

$\mathrm{N}_{2} \mathrm{O}$ is a frequently used, highly effective sedation option for therapeutic LPs in children at our institution. It appears to be comparable to propofol in terms of successful IT chemotherapy administration and traumatic LP incidence and, for many patients, can effectively replace propofol during most if not all LP procedures, which has important implications from a quality-of-life and safety standpoint. Future analyses will focus on further defining patient-related factors supporting $\mathrm{N}_{2} \mathrm{O}$ use early in the treatment course, assessing patient, provider, and parent experience, evaluating safety events by sedation type, and comparing encounter costs in lieu of sedation used.

Acknowledgments: The authors thank the 215 children, adolescents, and young adults with ALL whose treatment and sedation experiences contributed to the information gained in this study.

Disclosures: The authors have no financial relationships to disclose.

Grant support: None

Figure Legends:

FIGURE 1: Diagram of initial and subsequent sedation selection $\left(\mathrm{N}_{2} \mathrm{O}\right.$, propofol $)$ among children with a minimum of 5 therapeutic LPs performed in the outpatient setting. ALL, acute lymphoblastic leukemia; LP, lumbar puncture; IT, intrathecal; $\mathrm{N}_{2} \mathrm{O}$, nitrous oxide.

FIGURE 2: Bar chart detailing the trajectories of sedation selection across the first, second, third, penultimate, and final therapeutic LPs in children with ALL in the outpatient setting; LP, lumbar puncture; $\mathrm{N}_{2} \mathrm{O}$, nitrous oxide.

References

1. Richards S, Pui C-H, and Gaynon P. Systematic review and meta-analysis of randomized trials of central nervous system directed therapy for childhood acute lymphoblastic leukaemia. Pediatr Blood Cancer 2013; 60(2): 185-195.

2. Salzer WL, Burke MJ, Devidas M, et al. Impact of intrathecal triple therapy versus intrathecal methotrexate on disease-free survival for high-risk B-lymphoblastic leukemia: Children's Oncology Group Study AALL1131. J Clin Oncol 2020; 38(23): 2628-2638.

3. Angiolillo AL, Schore RJ, Kairalla JA, et al. Excellent outcomes with reduced frequency of vincristine and dexamethasone pulses in standard-risk B-lymphoblastic leukemia: results from Children's Oncology Group AALL0932. J Clin Oncol 2021; 39(13): 1437-1447.

4. Teachey DT and O'Connor D., How I treat newly diagnosed T-cell acute lymphoblastic leukemia and T-cell lymphoblastic lymphoma in children. Blood 2020; 135(3): 159-166.

5. Chidambaran V, Costandi A, and D'Mello A. Propofol: a review of its role in pediatric anesthesia and sedation. CNS Drugs 2015; 29(7): 543-563.

6. Hertzog JH, Dalton HJ, Anderson BD, et al. Prospective evaluation of propofol anesthesia in the pediatric intensive care unit for elective oncology procedures in ambulatory and hospitalized children. Pediatrics 2000; 106(4): 742-747.

7. Kim S, Hahn S, Jang M-J, et al. Evaluation of the safety of using propofol for paediatric procedural sedation: a systematic review and meta-analysis. Sci Rep 2019; 9(1): 122-145.

8. Hargens L, Slagerman K, Moertel C, et al. The use of nitrous oxide to treat pain of lumbar punctures in ambulatory pediatric leukemia and lymphoma patients. Blood 2006; 108(11): 3306.

9. Livingston M, Lawell M, and McAllister N. Successful use of nitrous oxide during lumbar punctures: a call for nitrous oxide in pediatric oncology clinics. Pediatr Blood Cancer 2017; 64(11): e26610

10. Tobias JD. Applications of nitrous oxide for procedural sedation in the pediatric population. Pediatr Emerg Care 2013; 29(2): 245-265.

11. Liu Q, Chai X-M, Zhang J-J, et al. A fixed nitrous oxide and oxygen mixture for analgesia in children with leukemia with lumbar puncture-induced pain: a randomized, double-blind controlled trial. J Pain Symptom Manage 2019; 57(6): 1043-1050. 
12. Zier JL and Maresh JR. Is nitrous oxide sedation an aerosol generating procedure? Pediatr Emerg Care 2020; 36(8): e484.

13. Whitlow PG, Saboda K, Roe DJ, et al. Topical analgesia treats pain and decreases propofol use during lumbar punctures in a randomized pediatric leukemia trial. Pediatr Blood Cancer 2015; 62(1): 85-90.

14. Hsiao H-J, Chen S-H, Jaing T-H, et al. Psychosocial interventions for reduction of distress in children with leukemia during bone marrow aspiration and lumbar puncture. Pediatr Neonatol 2019; 60(3): 278-284.

15. Liossi C and Hatira P. Clinical hypnosis in the alleviation of procedure-related pain in pediatric oncology patients. Int J Clin Exp Hypn 2003; 51(1): 4-28.

16. Eijlers R, Utens E, Staals L, et al. Systematic review and meta-analysis of virtual reality in pediatrics: effects on pain and anxiety. Anesth Analg 2019; 129(5): 1344-1353.

* The dataset on which this paper is based is too large to be retained or publicly archived with available resources, however they can be made available by contacting the author at Children's Minnesota.

\section{Hosted file}

Table 1.docx available at https://authorea.com/users/346727/articles/538952-a-naturalhistory-study-of-nitrous-oxide-versus-propofol-assisted-intrathecal-therapy-in-thetreatment-of-acute-lymphoblastic-leukemia

\section{Hosted file}

Table 2.docx available at https://authorea.com/users/346727/articles/538952-a-naturalhistory-study-of-nitrous-oxide-versus-propofol-assisted-intrathecal-therapy-in-thetreatment-of-acute-lymphoblastic-leukemia

\section{Hosted file}

Table 3.docx available at https://authorea.com/users/346727/articles/538952-a-naturalhistory-study-of-nitrous-oxide-versus-propofol-assisted-intrathecal-therapy-in-thetreatment-of-acute-lymphoblastic-leukemia 
Figure 1 Patient selection of sedation agents.

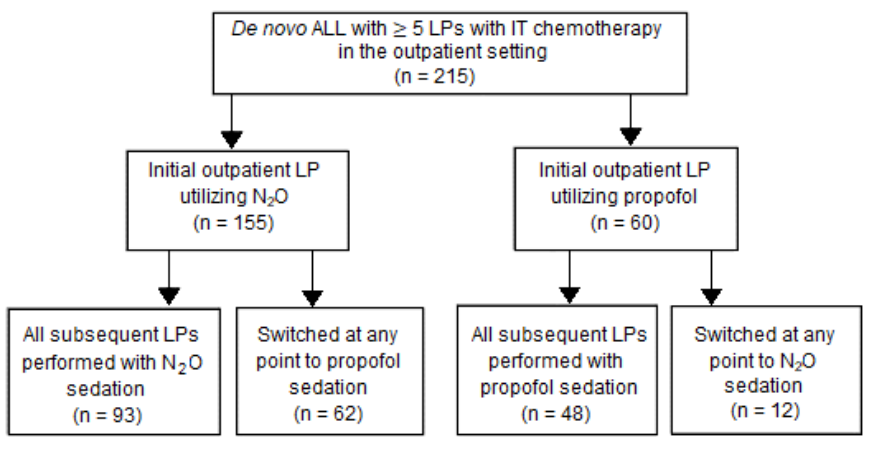


Figure 2 Trajectories of sedation selection across all LPs.

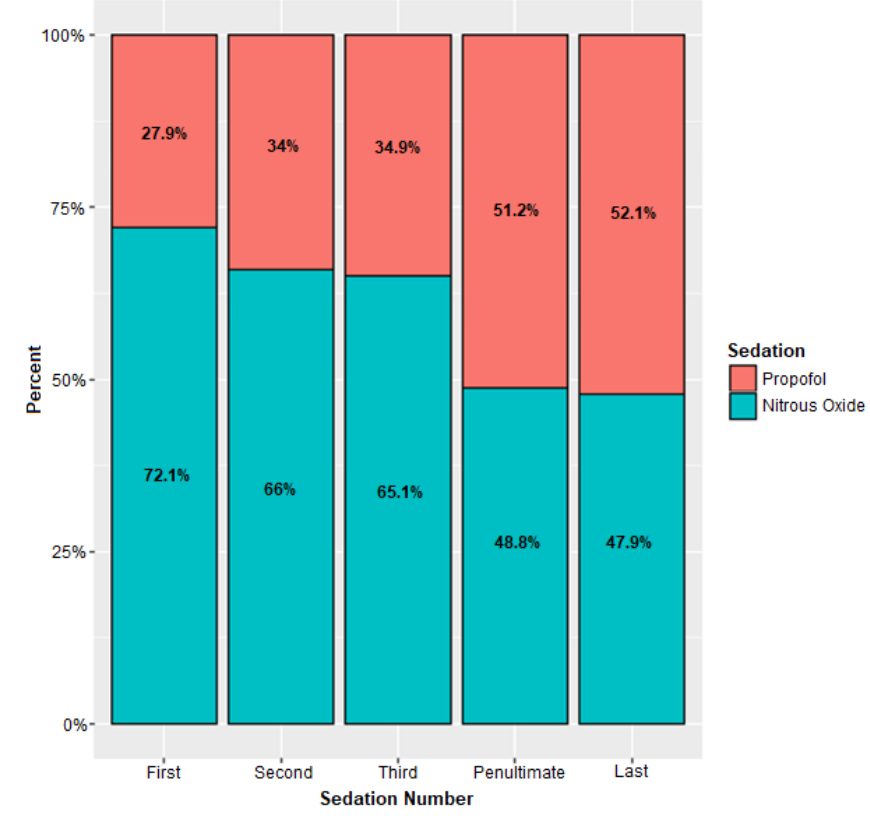

